\title{
Assessment of microbial carcass contamination of hunted wild boars
}

\author{
Jovan Mirceta $^{1} \cdot$ Jelena Petrovic $^{2} \cdot$ Milos Malesevic $^{3} \cdot$ Bojan Blagojevic $^{1}$. \\ Dragan Antic ${ }^{4}$ (i)
}

Received: 28 December 2016/Revised: 9 February 2017 / Accepted: 7 March 2017 /Published online: 15 March 2017

(C) The Author(s) 2017. This article is published with open access at Springerlink.com

\begin{abstract}
To investigate the microbiological conditions of hunted wild boar carcasses and factors that contribute to the microbial carcass contamination, skin and carcass meat swab samples from 210 hunted wild boars were collected from freshly shot animals. The mean aerobic colony counts (ACCs) and Enterobacteriaceae counts on the skin were 5.2 and $3.6 \log _{10} \mathrm{CFU} / \mathrm{cm}^{2}$, with $1.4 \%$ of animals' skin tested positive for Salmonella spp. Slightly higher mean ACC and Enterobacteriaceae counts of 5.4 and $3.8 \log _{10} \mathrm{CFU} / \mathrm{cm}^{2}$ were obtained from carcass meat with Salmonella spp. prevalence of $1.9 \%$. Inadequate hygiene practices in handling and dressing wild boar carcasses, such as evisceration in the laying position on the ground and practice of skin and interior carcass surface washing after evisceration, were found to have the most significant influence on the microbiological conditions of final carcasses. Therefore, these findings indicate the need for the implementation and strict adherence to good hygiene practice in hunting estates and game handling establishments.
\end{abstract}

Keywords Wild boars $\cdot$ Game meat $\cdot$ Microbial carcass contamination $\cdot$ Process hygiene $\cdot$ Hunting procedures

Dragan Antic

Dragan.Antic@liverpool.ac.uk

1 Department of Veterinary Medicine, Faculty of Agriculture, University of Novi Sad, Trg D. Obradovica 8, Novi Sad 21000, Serbia

2 Scientific Veterinary Institute, Rumenacki put 20, Novi Sad 21000, Serbia

3 Institute of Meat Hygiene, Meat Technology and Food Science, University of Veterinary Medicine, Veterinaerplatz 1, A 1210 Vienna, Austria

4 Institute of Veterinary Science, Faculty of Health and Life Sciences, University of Liverpool, Neston CH64 7TE, UK

\section{Introduction}

Game meat, including meat from wild boars, is gaining more significance in recent years as being perceived as healthier food. Wild boar meat products in Serbia are often not heat treated, but only dry cured, cold smoked and dried (i.e. traditional dried meats and dry fermented sausages). This emphasises the need of using raw meat of good hygiene and microbiological quality so to protect public health (Avagnina et al. 2012). In this respect, hunting estates (HEs), being primary producers, and approved game handling establishments (AGHEs), processing game meat and selling it to a market, have respective responsibilities in ensuring game meat safety and traceability (EC 2004).

Traditionally, wild boars are hunted either in open areas or in large enclosures. The microbiological quality of wild boar meat can vary greatly (Gill 2007), particularly due to the nature of harvesting and processing, which significantly differ from that of farm animals (Paulsen 2011). The health of animals before killing, the location of shot placement and the hygiene of carcass handling and dressing (from their collection to the chilling point) significantly influence the final microbiological quality of game meat (Paulsen 2011). Nevertheless, systematic studies on the impact of game carcass dressing techniques on the microbial contamination of resulting meat are lacking in the literature. Also, although animal coats are considered to be the most significant source of carcass meat microbial contamination in the case of domestic farm animals (Antic et al. 2011), there are no published studies on microbiological status of large game skin and/or on evaluation of its role in the contamination of large game carcass meat, apart from a recent pilot study on a limited number of wild boar animals (Mirceta et al. 2015).

The microbiological conditions of freshly shot wild boar carcasses have been evaluated in a very few studies, not only 
by both indicators of general contamination (Aerobic colony count, ACC) and faecal contamination (Enterobacteriaceae count $(\mathrm{EBC})$ ), but also by the presence of pathogenic bacteria (Atanassova et al. 2008; Avagnina et al. 2012; Mirceta et al. 2015). This includes Salmonella spp., which is considered as a relevant biological hazard for hunted wild game animals (Gortázar et al. 2007) and was assessed as of high priority in wild boar meat safety assurance (EFSA 2013). Such studies generate useful data that can be used in game meat risk assessment but are lacking in the literature (Paulsen et al. 2012).

Therefore, the main aim of this study was to investigate the microbiological conditions of hunted wild boar carcasses by analysing samples collected from freshly shot animals after evisceration and from specific hunting districts in the region of South-West Vojvodina. A further objective of this study was to investigate the impact of different factors, such as shooting location and hygienic practices (evisceration, skin washing and diaphragm and peritoneum removal), on microbial contamination of freshly shot wild boar carcasses, in order to make recommendations for the development and implementation of appropriate control measures.

\section{Materials and methods}

\section{Animals, hunting and dressing procedures}

The study was carried out in the periods between October and December of the hunting season 2015, in the region of SouthWest Vojvodina (northern province in Serbia). Samples were collected in eight different hunting estates (HEs, intensively managed large enclosures) which, along with their associated game handling establishments (GHEs), operate as approved food business operators. In total, 210 wild boars, freshly shot on organised, official hunts, were sampled in this study, with six HEs visited once and two HEs visited over 2 days. The hunts were usually performed by hunters taking fixed positions ("still hunting") and using rifle bullet for shooting (minimum calibre $7 \times 64 \mathrm{~mm}$ ). After the end of the hunt and collection of killed animals, evisceration was performed either in the field at the collection point in two HEs ( $32 \%$ of sampled animals), or killed animals were transported to their associated GHE where evisceration and further dressing occurred in their premises, in six HEs (68\% of sampled animals). In the latter case, the proximity of their GHEs allowed for evisceration to be done within $1.5 \mathrm{~h}$ from shooting. However, in all HEs, uneviscerated and/or eviscerated carcasses were transported in vehicles not equipped with a hanging frame, so were piled on top of each other during transport. If eviscerated in the field, animals were usually processed while lying on the ground, without being protected from the contamination originating from the soil and/or faeces. Inside GHEs' premises, most of the carcasses were eviscerated in a hanging position (while hanged on a hanging frame) and some of them in the lying position on the floor. As a measure for reducing abdominal contamination, especially in the case when abdominal shots had occurred, $90 \%$ of the carcasses had their diaphragm and peritoneum removed. However, skin and interior carcass surface washing practice after evisceration was also observed in three HEs (37\% of sampled animals). In all cases, period between killing and onset of refrigeration did not exceed $3 \mathrm{~h}$. Following the usual harvesting and dressing procedures, the carcasses were kept chilled skin-on for several days before despatching or further processing.

\section{Sampling procedures}

Samples from wild boar skin and carcass meat were collected after animals were transported to the collection point in the field or in the GHEs (depending on where evisceration took place) and within $1.5 \mathrm{~h}$ from shooting. Data were recorded for each sampled animal including (i) shooting location (correct shot placement or in the abdomen), (ii) weather conditions (rainy or dry) and (iii) the time that elapsed between killing and evisceration. Also, in order to assess the influence of the workers' dressing practices on the microbiological conditions of final carcasses, related information was recorded: (i) a level of workers' training and hygienic practices applied during evisceration and dressing of carcasses (or lack of thereof), (ii) evisceration technique used (in the lying or hanging position, in the field or inside GHE premises) and (iii) skin and interior carcass surface washing practice after evisceration.

Samples were taken by swabbing skin or interior carcass meat surface using the wet swab technique. Each sterile sponge (Nasco, Whirl-Pack, Fort Atkinson, WI, USA) was moistened with $10 \mathrm{ml}$ of maximum recovery diluent (MRD; Oxoid) prior to swabbing. Sterile gloves were used for each sample, to prevent cross-contamination. Wild boars' skins were sampled shortly before evisceration by swabbing approximately $1000 \mathrm{~cm}^{2}$ of skin surface (an area covering rump-perianal-flank-brisket-neck). Interior carcass meat surface swab samples were taken not more than 10 min after the evisceration and any other procedures (i.e. skin washing and/or diaphragm and peritoneum removal) were completed. Four carcass meat sites corresponding to the previously sampled skin (i.e. interior surface of the rump and flank, thorax and brisket) were sampled using sterile disposable square plastic template, which delineated $100 \mathrm{~cm}^{2}$ area and sponge-swabbed by five consecutive passes. The sampling sites were chosen according to ISO method 17604:2003 (ISO 2003) referred in the Regulation (EC) No. 1441/2007 (EC 2007). Swabs from each carcass were pooled and placed in a separate stomacher bag (Nasco, Whirl-Pack, $19 \times 30 \mathrm{~cm}$; Fort Atkinson) and transported chilled at $4{ }^{\circ} \mathrm{C}$ to the laboratory within $3 \mathrm{~h}$. 


\section{Microbiological analysis}

Maximum recovery diluent (MRD; Oxoid; $90 \mathrm{ml}$ ) was added to each bag containing a sponge swab and then homogenised with a stomacher (easyMIX, BioMérieux, France) for $1 \mathrm{~min}$. Then, decimal dilutions were made in MRD (ISO method 6887-1, ISO (1999). Sample homogenates and/or their appropriate dilutions were further analysed.

For ACC and Enterobacteriaceae enumeration, ISO procedures 4833:2008 (ISO 2008) and 21528-2:2009 (ISO 2009) were followed, respectively.

Isolation and determination of Salmonella spp. were performed according to the ISO 6579:2002 method (ISO 2002). Suspect colonies were purified on a nutrient agar and confirmed biochemically using API 20E kits (BioMérieux, France) and serologically using poly $\mathrm{O}$ antiserum (Pro-Lab Diagnostics, Canada).

\section{Data analyses}

For both skin and carcass meat samples, ACC and Enterobacteriaceae were calculated as $\mathrm{CFU} / \mathrm{cm}^{2}$ and converted to $\log _{10} \mathrm{CFU} / \mathrm{cm}^{2}$. For each group of samples, mean values and standard deviation as well as significance of differences between the mean values (the Student's $t$ test) based on $\log _{10}$ $\mathrm{CFU} / \mathrm{cm}^{2}$ values of both ACC and Enterobacteriaceae were calculated using IBM SPSS Statistics 20 (IBM, Armonk, NY, USA). The results of the statistical tests were considered significant for $P<0.05$.

\section{Results and discussion}

\section{Microbial contamination of wild boar skin and carcass meat}

Skin and carcass meat swab samples from a total of 210 freshly shot wild boars were collected from eight different HEs. The mean ACC and EBC on wild boar skin were 5.2 and $3.6 \log _{10}$ $\mathrm{CFU} / \mathrm{cm}^{2}$, ranging from 2.0 to $8.4 \log _{10}$ and 0.3 to $6.8 \log _{10}$ $\mathrm{CFU} / \mathrm{cm}^{2}$, respectively. Weather conditions did not significantly influence wild boar skin contamination. Slightly higher mean $\mathrm{ACC}$ and $\mathrm{EBC}$ were recovered from interior carcass meat surface and were 5.4 and $3.8 \log _{10} \mathrm{CFU} / \mathrm{cm}^{2}$ (ranged from 2.4 to $7.9 \log _{10}$ and 0.4 to $6.9 \log _{10} \mathrm{CFU} / \mathrm{cm}^{2}$ ), respectively (Table 1 ). In abattoirs slaughtering domestic animals, where spillage or leakage of intestinal content occurs rarely (and even if it does, it is managed by corrective action within HACCP), hide/skin is the main source of carcass contamination where dressed carcass gets contaminated with relatively a small proportion of hide/ skin bacterial load (Blagojevic et al. 2011). However, the finding that, on average, wild boar carcass meat from unskinned wild boars carried higher ACC and EBC levels than the skin is

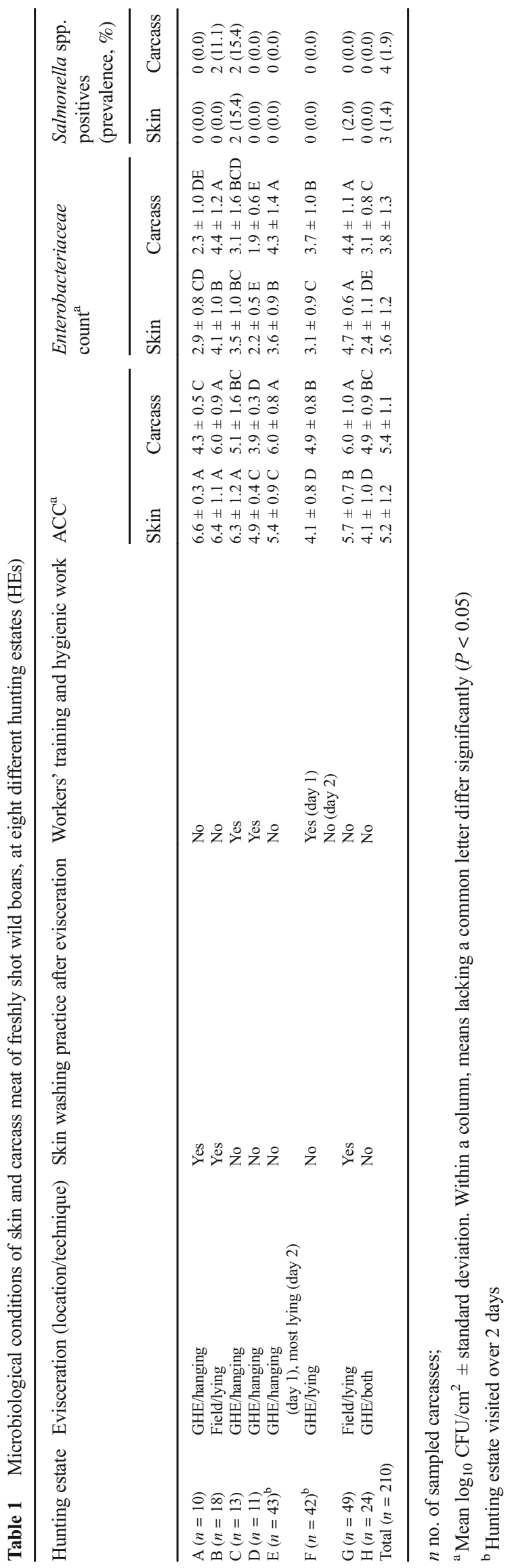


not so surprising considering the influence of ruptures of intestines as a consequence of shots in abdominal region (although overall not statistically significant, Table 2) and other unhygienic procedures (such as evisceration performed on soil forest ground followed by skin and interior carcass surface washing). Also, it is possible that the transfer of bacteria onto the sponge swab during sampling from naturally moistened carcass meat was much more intensive than from the skin often overlaid with dried mud and faeces (Blagojevic et al. 2012). Furthermore, swabbed area of skin was 2.5 times larger than swabbed area of meat, so it is likely that sponges were not capable of absorbing the same proportion of contamination per square centimetre. Other studies found lower ACC and EBC levels on wild boar carcasses. Avagnina et al. (2012) reported median carcass ACC level of $4.6 \log _{10} \mathrm{CFU} / \mathrm{cm}^{2}$ and EBC level of 3.0 $\log _{10} \mathrm{CFU} / \mathrm{cm}^{2}$, when using similar swab sampling procedures as it was used in our study. Lower carcass contamination was reported by Atanassova et al. (2008) with $3.2 \log _{10} \mathrm{CFU} / \mathrm{cm}^{2}$ of ACC and $2.1 \log _{10} \mathrm{CFU} / \mathrm{cm}^{2}$ of EBC (geometrical means), even though the authors used the excision sampling method (which usually yields higher microbial recovery) but from the surface of carcass meat after careful removal of small parts of the skin in sampled areas.

Large variations in carcass meat microbial contamination were observed between HEs, and differences were mainly significant $(P<0.05)$. The mean ACC and EBC ranged between HEs from 3.9 to $6.0 \log _{10}$ and 1.9 to $4.4 \log _{10} \mathrm{CFU} / \mathrm{cm}^{2}$, respectively (Table 1). HEs B, E and G handled carcasses contaminated with $>6$ logs of ACC and $>4$ logs of EBC (Table 1). The main reason for higher contamination of wild boar carcass meat in HEs B and G was likely a skin and interior carcass surface washing practice performed after evisceration and the fact that evisceration was performed in the field at the collection point, on the ground. HE E was characterised by poor, non- standardised hygienic practices (one third of the total number of carcasses eviscerated in the lying position on day 2 of sampling) and unskilled workers (Table 3).

The overall prevalence of Salmonella spp. on the skin of shot wild boars was $1.4 \%$, and the prevalence on carcass meat was $1.9 \%$ (Table 1). To the best of our knowledge, there are no published data on Salmonella presence of wild boars' skin. Also, the literature data on the prevalence of Salmonella on wild boar carcass meat are scarce and vary from the cases in Germany, Italy and Austria where this pathogen was not detected (Atanassova et al. 2008; Avagnina et al. 2012; Paulsen and Winkelmayer 2004) to $1.2 \%$ in Spain (Díaz-Sánchez et al. 2013). These studies are directly comparable to our study, as similar swab sampling technique was used, except in Atanassova et al. (2008) as described earlier. The lack of more detailed studies on Salmonella in wild boars makes it difficult to ascertain whether the skin represents an important source of wild boar meat contamination with this pathogen (as is the case with domestic red meat animals), in scenarios when all other hunting and dressing procedures have been properly conducted. With a very few animal skins and carcasses found to be Salmonella contaminated in our study (i.e. 3 and 4 out of 210, respectively, Table 1) and with no molecular methods used for source tracking, it is not possible to establish clear skin-carcass correlation in respect to this pathogen.

\section{Influence of anatomical shooting location on carcass meat microbial contamination}

In total, 73 animals (34.8\%) were shot non-expertly (i.e. shot in abdominal region), which was somewhere in between other two similar studies where $21 \%$ and $43 \%$ of wild boars were shot nonexpertly (Atanassova et al. 2008; Avagnina et al. 2012). Although the still hunting method was used, a significant number
Table 2 Influence of shooting location on the microbiological conditions of carcass meat from hunted wild boars investigated in hunting estates (HEs) where substantial number of animals was shot non-expertly (in the abdomen)

\begin{tabular}{lll}
\hline Factors investigated & $\mathrm{ACC}^{\mathrm{a}}$ & $\begin{array}{c}\text { Enterobacteriaceae } \\
\text { count }^{\mathrm{a}}\end{array}$ \\
\hline $\begin{array}{l}\text { Shooting location (overall, for 8 HEs) } \\
\quad \text { Correct shot placement }(n=137)\end{array}$ & $3.7 \pm 1.4 \mathrm{~A}$ \\
$\quad$ Shot in the abdomen $(n=73)$ & $5.3 \pm 1.2 \mathrm{~A}$ & $4.0 \pm 1.2 \mathrm{~A}$ \\
HE E & $5.5 \pm 1.0 \mathrm{~A}$ & $4.6 \pm 1.3 \mathrm{~A}$ \\
$\quad$ Correct shot placement $(n=22)$ & $6.1 \pm 0.6 \mathrm{~A}$ & $4.1 \pm 1.4 \mathrm{~A}$ \\
$\quad$ Shot in the abdomen $(n=21)$ & $5.9 \pm 1.0 \mathrm{~A}$ & $3.3 \pm 1.0 \mathrm{~B}$ \\
HE F & $4.7 \pm 0.9 \mathrm{~A}$ & $4.1 \pm 1.0 \mathrm{~A}$ \\
$\quad$ Correct shot placement $(n=25)$ & $5.1 \pm 0.7 \mathrm{~A}$ & $4.4 \pm 1.1 \mathrm{~A}$ \\
$\quad$ Shot in the abdomen $(n=17)$ & $5.9 \pm 1.0 \mathrm{~A}$ & $4.5 \pm 1.2 \mathrm{~A}$ \\
HE G & $6.2 \pm 0.7 \mathrm{~A}$ & $2.6 \pm 0.8 \mathrm{~B}$ \\
$\quad$ Correct shot placement $(n=41)$ & $4.6 \pm 1.2 \mathrm{~A}$ & $3.4 \pm 0.5 \mathrm{~A}$ \\
$\quad$ Shot in the abdomen $(n=8)$ & $5.2 \pm 0.7 \mathrm{~A}$ & \\
HE H & & \\
$\quad$ Correct shot placement $(n=10)$ & & \\
$\quad$ Shot in the abdomen $(n=14)$ & & \\
\hline & &
\end{tabular}


of participating non-experienced hunters likely contributed to such a high number of abdominal shots. Even though slightly higher ACC and EBC were determined from carcasses of nonexpertly shot animals, the difference was not statistically significant (Table 2). However, with respect to different HEs, the number of non-expertly shot animals notably varied and ranged from 0 to as high as $58 \%$ in $\mathrm{HE} \mathrm{H}$. When taking into account only the HEs where substantial number of animals was shot non-expertly, EBC from $\mathrm{HE} \mathrm{F}$ and $\mathrm{H}$ differed significantly from expertly shot animals and were higher by $0.8 \log _{10} \mathrm{CFU} / \mathrm{cm}^{2}$ (Table 2).

It is reasonable to expect that the location of the shot wound would have had great impact on the overall microbiological condition of carcass meat. Atanassova et al. (2008) found carcass ACC levels of $3.0 \log _{10} \mathrm{CFU} / \mathrm{cm}^{2}$ and Enterobacteriaceae levels of $1.8 \log _{10} \mathrm{CFU} / \mathrm{cm}^{2}$ after correct shot placement, compared with 3.9 logs of ACC and $2.4 \operatorname{logs}$ of EBC in wild boars shot in the abdomen. A similar observation was made by Avagnina et al. (2012) with respect to a significantly higher ACC level in animals shot in the abdomen. However, we believe that other confounding factors, such as poor hygienic practice during evisceration, and particularly evisceration on the ground and/or floor inside GHEs as well as skin washing the eviscerated carcasses, overshadowed the detrimental impact of abdominal shot on microbial carcass contamination of wild boars.
Influence of dressing practices on carcass meat microbial contamination

A range of different carcass handling and dressing practices, such as evisceration on the ground or while hanged, skin and interior carcass surface washing and peritoneum and diaphragm removal, were observed in the course of this study. To date, there seem to be no systematic studies on which game carcass dressing techniques actually result in a minimised microbial contamination of meat (Paulsen 2011).

With respect to the evisceration location, 32\% (67/210) of shot wild boars (from HEs B and G) were eviscerated in the field at the collection point while lying on the ground and without access to potable water. This resulted in the higher ACC and EBC determined on carcass meat by $0.9 \log _{10}$ $\mathrm{CFU} / \mathrm{cm}^{2}$ when compared to carcasses eviscerated inside GHE premises of other HEs, regardless of the technique used $(P<0.05$, Table 3). Furthermore, when using the same evisceration technique (in lying position) but at different locations/ conditions (in the field without access to clean water or inside GHE premises using better hygiene), a significant increase in microbial contamination with ACC and Enterobacteriaceae $(P<0.05)$ of $0.9 \log _{10}$ and $0.5 \log _{10} \mathrm{CFU} / \mathrm{cm}^{2}$, respectively, was determined in the case of field evisceration (Table 3 ).
Table 3 Influence of different investigated carcass dressing practices on the microbiological conditions of carcass meat from hunted wild boars

\begin{tabular}{|c|c|c|}
\hline Factors investigated & $\mathrm{ACC}^{\mathrm{a}}$ & $\begin{array}{l}\text { Enterobacteriaceae } \\
\text { count }^{\mathrm{a}}\end{array}$ \\
\hline \multicolumn{3}{|c|}{ Evisceration location overall $(n=210)$} \\
\hline In the field $(n=67)$ & $6.0 \pm 0.9 \mathrm{~A}$ & $4.4 \pm 1.1 \mathrm{~A}$ \\
\hline Inside GHE premises ( $n=143$ ) & $5.1 \pm 1.1 \mathrm{~B}$ & $3.5 \pm 1.3 \mathrm{~B}$ \\
\hline \multicolumn{3}{|c|}{ Evisceration in the lying position $(n=139)$} \\
\hline In the field $(n=67)$ & $6.0 \pm 0.9 \mathrm{~A}$ & $4.4 \pm 1.1 \mathrm{~A}$ \\
\hline Inside GHE premises $(n=72)$ & $5.1 \pm 0.9 \mathrm{~B}$ & $3.9 \pm 1.3 \mathrm{~B}$ \\
\hline \multicolumn{3}{|c|}{ Evisceration technique used overall $(n=210)$} \\
\hline Lying position $(n=139)$ & $5.5 \pm 1.0 \mathrm{~A}$ & $4.1 \pm 1.2 \mathrm{~A}$ \\
\hline Hanging position $(n=71)$ & $5.2 \pm 1.3 \mathrm{~B}$ & $3.1 \pm 1.3 \mathrm{~B}$ \\
\hline \multicolumn{3}{|c|}{$\begin{array}{l}\text { Evisceration technique used inside GHE premises } \\
\quad(n=143)\end{array}$} \\
\hline Lying position $(n=72)$ & $5.1 \pm 0.9 \mathrm{~A}$ & $3.9 \pm 1.3 \mathrm{~A}$ \\
\hline Hanging position $(n=71)$ & $5.2 \pm 1.3 \mathrm{~A}$ & $3.1 \pm 1.3 \mathrm{~B}$ \\
\hline \multicolumn{3}{|c|}{$\begin{array}{l}\text { Skin and interior carcass surface washing } \\
\text { practice after evisceration }(n=210)\end{array}$} \\
\hline Yes $(n=77)$ & $5.8 \pm 1.1 \mathrm{~A}$ & $4.1 \pm 1.3 \mathrm{~A}$ \\
\hline No $(n=133)$ & $5.2 \pm 1.1 \mathrm{~B}$ & $3.6 \pm 1.3 \mathrm{~B}$ \\
\hline \multicolumn{3}{|c|}{$\begin{array}{l}\text { Practice of diaphragm and peritoneum } \\
\text { removal }(n=210)\end{array}$} \\
\hline Yes $(n=188)$ & $5.4 \pm 1.1 \mathrm{~A}$ & $3.7 \pm 1.3 \mathrm{~B}$ \\
\hline No $(n=22)$ & $5.5 \pm 0.8 \mathrm{~A}$ & $4.6 \pm 1.3 \mathrm{~A}$ \\
\hline \multicolumn{3}{|l|}{$\begin{array}{l}\text { Difference in day of sampling/ } \\
\text { practice observed }^{\mathrm{b}}\end{array}$} \\
\hline HE E day $1(n=20)$ & $6.3 \pm 1.0 \mathrm{~A}$ & $3.2 \pm 0.9 \mathrm{~B}$ \\
\hline HE E day $2(n=23)$ & $5.7 \pm 0.5 \mathrm{~B}$ & $5.3 \pm 0.9 \mathrm{~A}$ \\
\hline HE F day $1(n=21)$ & $4.5 \pm 0.9 \mathrm{~B}$ & $2.9 \pm 0.9 \mathrm{~B}$ \\
\hline HE F day $2(n=21)$ & $5.3 \pm 0.5 \mathrm{~A}$ & $4.4 \pm 0.6 \mathrm{~A}$ \\
\hline
\end{tabular}


With respect to the evisceration technique used, 66\% (139/ 210 ) of shot wild boars were eviscerated in the lying position (either in the field on the ground or on the floor inside GHE premises). The contamination of the body cavity and muscle tissues had not been prevented in most cases when eviscerated in the lying position, which was reflected in an increase in microbial contamination on carcass meat by $0.3 \log _{10}$ and 1.0 $\log _{10} \mathrm{CFU} / \mathrm{cm}^{2}$ of ACC and Enterobacteriaceae $(P<0.05)$, respectively, when compared with $34 \%$ (71/210) of carcasses eviscerated in hanging position and all inside GHE premises. A similar relationship was observed when comparing carcass microbial counts obtained from carcasses eviscerated inside GHE premises only, with $3.1 \log _{10}$ and $3.9 \log _{10} \mathrm{CFU} / \mathrm{cm}^{2}$ of Enterobacteriaceae recovered from carcasses eviscerated when hanged or lying, respectively $(P<0.05$, Table 3$)$. If carried out improperly, evisceration poses a high risk of microbial carcass contamination due to gut rupture and spillage of gut contents. This, alongside with improper (abdominal) shot and inadequate carcass chilling, is considered to be of the highest importance for the microbiological quality of final game meat products (Gill 2007; Paulsen et al. 2012). Therefore, an evisceration while carcasses are hanged and inside GHE premises where hygienic procedures are adhered to has its advantage over evisceration in field conditions and/or when on ground/floor, as the contamination of the body cavity and muscle tissues with soil and/or faeces is easier to avoid or minimise (Paulsen 2011). If, however, wild boars have to be eviscerated in the field due to remoteness of the GHE, the most recommended practice would be to eviscerate them in the hanging position (Paulsen 2011).

However, an unusual practice observed in three HEs (77 sampled animals) was skin and interior carcass surface washing after evisceration. Washing using a pressure washer was performed to "clean" skin-on wild boar carcasses before subjecting them to a chilling. Nevertheless, this unhygienic practice had as a consequence generation of a heavily contaminated aerosol and direct microbial transmission from the skin to interior carcass surfaces, which significantly increased ACC and $\mathrm{EBC}$ on carcass meat by more than $0.5 \operatorname{logs}$ on average $(P<0.05$, Table 3$)$. This was particularly noticeable in wild boars from HEs B and $\mathrm{G}$, in which evisceration had been also performed in the field, while carcasses lying on the ground (Table 1). Workers in these two HEs had not been properly trained and showed a significant lack of awareness with respect to hygienic practises in handling and dressing wild boar carcasses. Washing (and subsequent drying) of live dirty cattle is standard pre-slaughter practice in some countries and abattoirs, with questionable antimicrobial efficiency but aiming to remove visible dirt so to facilitate dehiding process (Blagojevic et al. 2012).

On the other hand, practice of peritoneum and diaphragm removal, which is used to reduce abdominal contamination arising from improperly placed shot and/or evisceration process, was performed on most carcasses (around 90\% of them) and significantly improved their microbiological conditions with respect to the EBC $(P<0.05$, Table 3$)$. Nevertheless, the fact that this control measure itself could not have contributed to a better microbiological condition of resulting carcasses (Table 3) clearly indicates that little can be improved in the case when other dressing practices had been inadequate, like in our study.

The importance of proper training of workers and their strict adherence to the good hygiene practices while handling and dressing wild boar carcasses was well determined in the two HEs ( $\mathrm{E}$ and $\mathrm{F}$ ) that were visited over 2 days. In both HEs, similar number of animals was shot in abdomen on both days and skin washing was not used; therefore, the only difference between the two processing days in each one of them was solely down to workers' level of previous training and hygienic practice used. Notably different dressing practices were seen on both days, which were reflected in significantly different levels of microbial contamination (Table 3). For example, the $\mathrm{EBC}$ on day 2 in HE E were as high as $5.3 \log _{10} \mathrm{CFU} /$ $\mathrm{cm}^{2}$ and were higher than from the day 1 by more than 2 $\log _{10} \mathrm{CFU} / \mathrm{cm}^{2}$. The underlying reason could have been the fact that workers on day 2 were using very poor dressing practice, with most of the carcasses eviscerated in the laying position on the floor inside the premises and without removing their diaphragm and peritoneum, but also lacking knife and hand hygiene. On the other hand, all carcasses processed on day 1 were eviscerated while hanged with their diaphragm and peritoneum removed afterwards, with hand and knife washing used to some extent. In HE F, similar evisceration technique (i.e. in the laying position on the floor inside the premises) and diaphragm and peritoneum removal procedure were performed on both days. However, different workers were employed that demonstrated substantially different levels of hygiene (i.e. on day 1 properly trained workers thoroughly adhered to the GHP principles as opposed to the day 2 when untrained workers performed very poor hygiene work). This resulted in the $1.5 \mathrm{log}$ difference in EBC levels (Table 3).

Despite all efforts made and hygienic work in carcass handling and dressing in some HEs, as well as generally lower microbial counts obtained in them, the microbiological conditions of most wild boar carcasses were far from desired and well over the limits for microbiological process hygiene criteria set for domestic pigs that we used for the purpose of comparison in this study (Table 4). In this respect, it is clear that adherence to the usual good hygiene practice principles might not be sufficient in this challenging game meat production process to ensure appropriate microbiological quality of the final product. 
Table 4 Compliance of ACC and Enterobacteriaceae counts obtained from wild boar carcasses $(n=210)$ when compared with process hygiene criteria set for dressed carcasses of domestic pigs according to the Regulation (EC) No. 1441/2007 (EC 2007)

\begin{tabular}{lll}
\hline $\begin{array}{l}\text { Categories of process } \\
\text { hygiene criteria }\end{array}$ & ACC & Enterobacteriaceae count \\
\hline Satisfactory $\left(<4^{\mathrm{a}} ;<2 \log _{10} \mathrm{CFU} / \mathrm{cm}^{2 \mathrm{~b}}\right)$ & $33(15.7 \%)$ & $24(11.4 \%)$ \\
Acceptable $\left(4-5^{\mathrm{a}} ; 2-3 \log _{10} \mathrm{CFU} / \mathrm{cm}^{2 \mathrm{~b}}\right)$ & $36(17.1 \%)$ & $44(21.0 \%)$ \\
Unsatisfactory $\left(>5^{\mathrm{a}} ;>3 \log _{10} \mathrm{CFU} / \mathrm{cm}^{2 \mathrm{~b}}\right)$ & $141(67.2 \%)$ & $142(67.6 \%)$ \\
\hline
\end{tabular}

${ }^{a}$ Limits for ACC

${ }^{\mathrm{b}}$ Limits for Enterobacteriaceae count
Therefore, in addition to fundamental process hygienebased microbial risk reduction measures, it might be worth considering certain procedures such as skin and/or carcass decontamination (Antic et al. 2011). These could be used as complementary 'multiple hurdle' strategies to control microbial contamination of wild boar carcassesbut certainly cannot be substitute for good hygienic practice (EFSA 2013).

\section{Compliance of microbial counts obtained from wild boar carcasses when compared with process hygiene criteria set for dressed carcasses of domestic pigs}

In order to verify process hygiene of wild boar carcass dressing and to improve meat safety, setting of microbiological criteria for wild boar meat would be useful (Paulsen 2011). Carcasses of wild boar are usually skinned (if not chilled as skin-on carcasses) whereas the carcasses of domestic pigs are usually scalded, dehaired and singed, and the skin remains the part of final carcass. Therefore, process hygiene criteria (PHC) values set in the EU legislation for livestock in which coat is always removed in abattoirs (e.g. cattle) might be more suitable for extrapolation on wild boar meat carcasses. Nevertheless, if the individual results of wild boar carcass contamination are compared with current $\mathrm{PHC}$ for dressed domestic pig carcasses (EC 2007), roughly two thirds of carcasses tested in this study would fall into unsatisfactory category with respect to both ACC and EBC (Table 4). Even if an upper limit for ACC is set at 6 logs, as suggested by Paulsen (2011), 61 samples (29\%) would still fall under unsatisfactory category. On the other hand, testing for Salmonella spp. presence on dressed domestic pig carcasses is also used as PHC with values set at $3 / 50$ carcasses allowed to be positive (EC 2014). In that respect, the sporadic finding of Salmonella-positive carcasses (i.e. 2/18 in HE B and 2/13 in HE C) would likely indicate that the process hygiene in these two HEs could be characterised as unsatisfactory and in remaining six HEs as satisfactory - even though a majority of them would not be compliant with respect to the ACC and EBCs (Table 1). This inconsistency between the results obtained from testing for indicators of general and faecal contamination and testing for pathogen also confirms inappropriateness of the occurrence-based pathogen testing in assessing process hygiene performances (Blagojevic et al. 2011). This could be particularly relevant for HEs operating on a small scale and which may be exempted from the usual microbiological testing.

\section{Conclusions}

This study identifies and analyses for the first time an influence that a range of different wild boar carcass handling and dressing practices have on its microbiological condition. The findings that the majority of wild boar carcasses had very high microbial counts as expressed through ACC and Enterobacteriaceae emphasise the need for the implementation and strict adherence to good hygiene practice in hunting estates and game handling establishments. Some practices, such as skin and interior carcass surface washing and evisceration on the ground in the lying position, should be strongly discouraged, and more needs to be done with respect to the training of hunters and workers involved in the wild boar meat chain. Approved GHEs have respective responsibilities in ensuring game meat safety and should comply with all regulatory requirements when placing game meat on the market. To facilitate this and make it more transparent and measurable, microbiological PHC should be developed and set for game meat as it is currently the case with other meat-producing animals. This would allow for AGHEs to have clear performance objectives enabling them to operate in a satisfactory manner, in order to achieve desired microbiological quality of the final product and protect public health.

Acknowledgements The authors wish to thank the hunters and managers of all hunting districts and game-handling establishments used for this research for their collaboration and help in animal sampling. The study was funded by Serbian Ministry of Education, Science and Technological Development projects TR 31084 and TR 31034.

Open Access This article is distributed under the terms of the Creative Commons Attribution 4.0 International License (http:// creativecommons.org/licenses/by/4.0/), which permits unrestricted use, distribution, and reproduction in any medium, provided you give appropriate credit to the original author(s) and the source, provide a link to the Creative Commons license, and indicate if changes were made. 


\section{References}

Antic D, Blagojevic B, Buncic S (2011) Treatment of cattle hides with Shellac solution to reduce hide-to-beef microbial transfer. Meat Sci 88:498-502

Atanassova V, Apelt J, Reich F, Klein G (2008) Microbiological quality of freshly shot game in Germany. Meat Sci 78:414-419

Avagnina A, Nucera D, Grassi M, Ferroglio E, Dalmasso A, Civera T (2012) The microbiological conditions of carcasses from large game animals in Italy. Meat Sci 91:266-271

Blagojevic B, Antic D, Ducic M, Buncic S (2011) Ratio between carcassand skin-microflora as an abattoir process hygiene indicator. Food Control 22:186-190

Blagojevic B, Antic D, Ducic M, Buncic S (2012) Visual cleanliness scores of cattle at slaughter and microbial loads on the hides and the carcases. Vet Rec 170:563

Díaz-Sánchez S et al (2013) Prevalence of Shiga toxin-producing Escherichia coli, Salmonella spp. and Campylobacter spp. in large game animals intended for consumption: relationship with management practices and livestock influence. Vet Microbiol 163:274-281

EC (2004) Regulation (EC) No. 853/2004 of the European Parliament and of the Council of 29 April 2004 laying down specific rules for food of animal origin. Official Journal of the European Union L 226: 93-127

EC (2007) Regulation (EC) No. 1441/2007 of 5 December 2007 amending Regulation (EC) No. 2073/2005 on microbiological criteria for foodstuffs. Official Journal of the European Union L $322 / 12$

EC (2014) Regulation (EU) No. 217/2014 of 7 March 2014 amending Regulation (EC) No. 2073/2005 as regards Salmonella in pig carcases. Official Journal of the European Union L 69/93

EFSA (2013) Scientific opinion on the public health hazards to be covered by inspection of meat from farmed game. EFSA J 11:3264

Gill C (2007) Microbiological conditions of meats from large game animals and birds. Meat Sci 77:149-160
Gortázar C, Ferroglio E, Höfle U, Frölich K, Vicente J (2007) Diseases shared between wildlife and livestock: a European perspective. Eur J Wildl Res 53:241-256

ISO (1999) ISO 6887-1:1999, Microbiology of food and animal feeding stuffs - preparation of test samples, initial suspension and decimal dilutions for microbiological examination - part 1: general rules for the preparation of the initial suspension and decimal dilutions. International Organization for Standardization

ISO (2002) ISO 6579:2002, Microbiology of food and animal feeding stuffs - horizontal method for the detection of Salmonella spp. International Organization for Standardization

ISO (2003) ISO 17604:2003, Microbiology of food and animal feeding stuffs - carcass sampling for microbiological analysis. International Organization for Standardization

ISO (2008) ISO 4833:2008, Microbiology of food and animal feeding stuffs - horizontal method for the enumeration of micro organisms - colony-count technique at $30 \mathrm{C}$. International Organization for Standardization:1-9

ISO (2009) ISO 21528-2: 2009, Microbiology of food and animal feeding stuffs - horizontal methods for detection and enumeration of Enterobacteriaceae - part 2: colony-count method. International Organization for Standardization

Mirceta J, Petrovic J, Blagojevic B, Malesevic M, Antic D (2015) The microbiological status of carcasses from wild boar in Serbia. P Food Sci 5:199-202

Paulsen P (2011) Hygiene and microbiology of meat from wild game: an Austrian view. In: Paulsen P, Bauer, A., Vodnansky, M., Winkelmayer, R., Smulders, F.J.M. (ed) Game meat hygiene in focus: microbiology, epidemiology, risk analysis and quality assurance. Wageningen Academic Publishers, Wageningen, pp. 19-37

Paulsen P, Winkelmayer R (2004) Seasonal variation in the microbial contamination of game carcasses in an Austrian hunting area. Eur J Wildl Res 50:157-159

Paulsen P, Smulders F, Hilbert F (2012) Salmonella in meat from hunted game: a central European perspective. Food Res Int 45:609-616 